\title{
ARTICLE OPEN \\ Comparison of the efficacy of ciclesonide with that of budesonide in mild to moderate asthma patients after step-down therapy: a randomised parallel-group study
}

Kuo-Chin Chiu ${ }^{1,7}$, Yen-Li Chou ${ }^{2,7}$, Jeng-Yuan Hsu ${ }^{3,7}$, Ming-Shian Lin ${ }^{4,7}$, Ching-Hsiung Lin ${ }^{5,7}$, Pai-Chien Chou ${ }^{6}$, Chun-Liang Chou ${ }^{6}$, Chun-Hua Wang ${ }^{6}$ and Han-Pin Kuo ${ }^{6}$

BACKGROUND: Inhaled corticosteroids (ICSs) are widely used in asthma control. Ciclesonide (CIC) is an ICS with on-site lung activation for potent anti-inflammatory activity.

AIMS: This study aimed to compare the clinical benefit of CIC with budesonide (BUD) in step-down therapy.

METHODS: A total of 150 patients with mild-to-moderate asthma well controlled by a combination of ICS and long-acting $\beta_{2}-$ agonist were randomised to receive either CIC $320 \mu \mathrm{g}(n=75)$ once daily or 2 inhalations of BUD $200 \mu \mathrm{g}(n=75)$ twice daily for 12 weeks. The forced expiratory volume in $1 \mathrm{~s}\left(\mathrm{FEV}_{1}\right)$, maximum mid-expiratory flow (MMEF) and asthma control test (ACT) scores were measured. Ranked stratification of patients and physicians was assessed.

RESULTS: Drug adherence was significantly higher in the CIC group than in the BUD group (76.0\% vs. 58.7\%, $P=0.03)$. The FEV 1 and

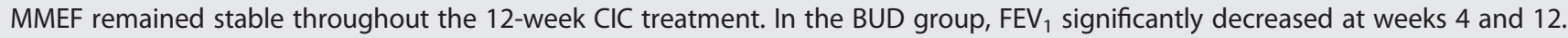
MMEF had a higher value in the CIC group than in the BUD group. Both patients and physicians ranked CIC over BUD.

CONCLUSIONS: CIC is more effective and has better drug adherence than BUD as step-down treatment when asthma is well controlled by combination therapy.

npj Primary Care Respiratory Medicine (2014) 24, Article number: 14010; doi:10.1038/npjpcrm.2014.10; published online 20 May 2014

\section{INTRODUCTION}

Asthma is a chronic airway disease characterised by airway inflammation, bronchoconstriction and increased airway responsiveness. ${ }^{1-3}$ Inhaled corticosteroids (ICS) control chronic inflammation and produce significant increases in morning and evening peak expiratory flows. ${ }^{4}$ ICS may be used as the first choice in controlling mild to moderate asthma and usually exhibits a good response.

Ciclesonide $(\mathrm{CIC})$ itself lacks appreciable activity and can be considered a prodrug. ${ }^{5-7}$ On inhalation, $\mathrm{CIC}$ is converted in the lungs by endogenous esterases to its active metabolite, desisobutyryl-CIC (des-CIC), which has a high receptor affinity and forms reversible conjugates with lipids within the lung. ${ }^{8}$ Moreover, CIC possesses other favourable pharmacokineticpharmacodynamic properties, such as a reported systemic bioavailability of $<1 \% .{ }^{9-12}$ The $\mathrm{CIC}$ is formulated in hydrofluoroalkane solutions, which can be deposited $>50 \%$ into the lower airways and distributed substantially to the small airways, ${ }^{13}$ with only minimum deposition in the oropharynx area. ${ }^{14}$ Another advantage of small-particle ICS is that it reaches the small airways and alveoli $^{15}$ and consequently results in anti-inflammation, including decreased levels of alveolar and bronchial exhaled nitric oxide $^{7,16}$ and attenuated infammatory markers in the exhaled breath condensate. ${ }^{16}$
Asthma management guidelines recommend a step-down strategy when asthma has been well controlled after an initial treatment of 3 months. ${ }^{17}$ A recent systematic review with a metaanalysis stated that discontinuing long-acting $\beta_{2}$-agonist (LABA) therapy in adults and older children with asthma controlled with a combination of ICS and LABAs results in increased asthmaassociated impairment. ${ }^{18}$ On the other hand, there are concerns over the safety of LABAs that has led to the recommendation by the US Food and Drug Administration that LABA be discontinued once asthma is controlled by combination therapy and that treatment with ICS alone should be the long-term treatment for asthma control. ${ }^{19}$ In the sysytematic review by Brozek et al., ${ }^{18}$ the studies reviewed maintained their patients on either budesonide (BUD) or fluticasone inhaler alone after the LABA component was discontinued.

This study posits that the use of a new formulated $\mathrm{CIC}$ could provide better control of asthma during LABA step-down therapy. In our study, patients stepped down from combination therapy to mono-ICS with the same dosage of ICS. However, until now, no comparison assessing the efficacy of step-down therapy from ICS and LABA combination to ICS only by using inhaled CIC alone in patients with asthma has been studied. Thus, in this study, we assessed and compared the efficacy and drug adherence of once-daily CIC at $320 \mu \mathrm{g}$ with twice-daily BUD at $400 \mu \mathrm{g}$ in treating mild to moderate asthma patients after step-down therapy.

\footnotetext{
${ }^{1}$ Division of Chest, Department of Internal Medicine, Poh-Ai Hospital, Luodong, Taiwan; ${ }^{2}$ Department of Thoracic Medicine, Chang Gung Memorial Hospital, Chiayi, Taiwan; ${ }^{3}$ Division of Chest, Department of Internal Medicine, Taichung Veterans General Hospital, Taichung, Taiwan; ${ }^{4}$ Department of Pulmonary and Critical Care Medicine, Chia-Yi Christian Hospital, Chiayi, Taiwan; ${ }^{5}$ Department of Chest Medicine, Changhua Christian Hospital, Changhua, Taiwan and ${ }^{6}$ Department of Thoracic Medicine, Chang Gung Memorial Hospital, Taipei, Taiwan.
}

Correspondence: C-H Wang (wchunhua@ms7.hinet.net) and H-P Kuo (q8828@ms11.hinet.net)

${ }^{7}$ These authors contributed equally to this work.

Received 5 August 2013; revised 17 January 2014; accepted 14 February 2014 


\section{MATERIALS AND METHODS}

Study design

This was a multicentre, open-label, randomised, parallel-controlled study evaluating the efficacy of $320 \mu \mathrm{g}$ Alvesco QD (Nycomed GmbH, Konstanz, Germany) with $400 \mu \mathrm{g}$ Duasma (Boehringer Ingelheim KG, Ingelheim, Germany) BID in patients with mild to moderate asthma after step-down therapy. The trial took place from April 2009 to June 2010. The inclusion criteria were as follows: male or female outpatients; nonsmokers; exsmokers with a smoking history of $<10$ packs per year; age $\geqslant 16$ years; and a documented clinical history of reversible airway obstruction with an increase in forced expiratory volume in $1 \mathrm{~s}\left(\mathrm{FEV}_{1}\right)$ of $\geqslant 12 \%$ and more than $200 \mathrm{ml}$, obtained $15 \mathrm{~min}$ after inhalation of salbutamol $(400 \mu \mathrm{g}){ }^{20}$ Patients were well controlled (asthma control test $(A C T)$ score $\geqslant 21$ ) and regularly used combination therapy at a dose of Symbicort (AstraZeneca, Södertälje, Sweden) (formoterol $4.5 \mu \mathrm{g}+\mathrm{BUD} 160 \mu \mathrm{g}) 2$ puffs twice daily or Seretide (GlaxoSmithKline, Brentford, UK) (salmeterol $50 \mu \mathrm{g}+$ fluticasone propionate $250 \mu \mathrm{g}) 1$ puff twice daily for at least 3 months before entry. Exclusion criteria were as follows: current smokers or smoking history of $>10$ packs per year; a lower respiratory tract infection within the last 4 weeks; taking oral or parenteral corticosteroids for at least 4 weeks prior to Visit 1; or recent acute exacerbations of asthma or uncontrolled disease. The study protocol was approved by the Institutional Review Board of Chang Gung Memorial Hospital (IRB No. 97-2157A3). Written informed consent was obtained from all patients.

During the 1-week run-in period, eligible patients received only the equivalent dose of ICSs (either BUD or fluticasone) with step-off LABAs, and salbutamol was used as a rescue medicine. After the run-in period, all patients who satisfied the entry criteria discontinued their usual inhaled medicine and replaced it with the study medication while continuing to use inhaled salbutamol as a rescue medicine. As the lung distribution of ICS formulated in a metered-dose inhaler is less than that of hydrofluoroalkane, ${ }^{13}$ the equivalent corcosteroid dose of BUD was applied as twice that of ciclesonide in this study. Eligible patients were randomised to receive either CIC $(160 \mu \mathrm{g})$ at 2 puffs once daily or BUD $(200 \mu \mathrm{g})$ at 2 puffs twice daily (Figure 1). At the end of the 12-week treatment period, patients stopped the study medication and appropriate asthma medication was then prescribed by the investigator.
Patient population

Of the 162 patients with asthma who were approached, 8 refused and 4 failed the initial screening during enrolment (Figure 2a). Figure 2 gives an overview of the patient disposition. Four (22.2\%) in the CIC group and 19 $(65.0 \%)$ in the BUD group $(P=0.007)$ did not complete the treatment because of poor control of asthma (Figure 2a), manifesting as daytime symptoms more than twice a week, nocturnal attacks or waking, need for rescue medicine more than twice a week, or limitation of daily activities because of asthmatic symptoms.

\section{Primary and secondary objectives}

To compare the effectiveness of CIC with BUD in treating asthmatic patients, the primary efficacy variable was the improvement in $\mathrm{FEV}_{1}$ at the end of the treatment period ( 12 weeks). Secondary efficacy included the measurements of forced vital capacity (FVC) and maximum mid-expiratory flow (MMEF) through the treatment period. Secondary asthma control variables included the ACT score, adherence to the study, and measurements of satisfaction rating by patients and physicians of $\mathrm{CIC}(160 \mu \mathrm{g})$ at 2 puffs once daily compared with BUD $(200 \mu \mathrm{g})$ at 2 puffs twice daily in asthmatic patients.

\section{Pulmonary function test}

At Visits 1, 2, 3, 4 and 5, the highest of the three technically acceptable measurements of FEV 1 were recorded. The FVC, FEV 1 and MMEF measurements were recorded using the same spirometer throughout the study, and were taken in the morning, usually $12 \mathrm{~h}$ after the last dose of the study medication, and at the same time on each visit day.

\section{Asthma control test}

The ACT was a patient-completed questionnaire that evaluated the following five items in the preceding weeks: limitation of activities; shortness of breath; awakenings at night; use of reliever medication; and patient's perception of asthma control. ${ }^{21,22}$ Each question had five response options, resulting in a score range of 1-5. The sum of all scores yields the total ACT score, ranging from 5 (poor asthma control) to 25
Patients receiving symbicort (formoterol $4.5 \mu \mathrm{g}$ +budesonide $160 \mu \mathrm{g}) 2$ puffs twice daily or seretide (salmeterol $50 \mu \mathrm{g}+$ fluticasone propionate $250 \mu \mathrm{g}) 1$ puff twice daily for at least 3 months and ACT score $\geq 21$ 
(optimal asthma control). The ACT test has been validated in patients aged 12 years and older. Patients were given an ACT to complete on visits 2, 4 and 5. The investigator explains the test to the patients, which enables the patients to complete the ACT by noting down the responses for each item on a scale of $1-5$.

Patients' satisfaction rating and physicians' assessment

At the end of the treatment, patients were asked to rate their overall satisfaction (very satisfied, satisfied, neutral, dissatisfied, very dissatisfied) with the trial medication in managing asthma. The physicians' assessment was also recorded to obtain their overall satisfaction rating (very satisfied, satisfied, neutral, dissatisfied, very dissatisfied).

\section{Statistical analysis}

Data were expressed as mean \pm s.d. The demographic details were summarised with descriptive statistics. We used Prism 5 software (GraphPad Software, La Jolla, CA, USA) for data analysis. Fisher's exact test (qualitative data) or analysis of variance (quantitative data) was employed to test the homogeneity of the treatment groups. As the data of treatment groups were multiple repeated measurements, generalised

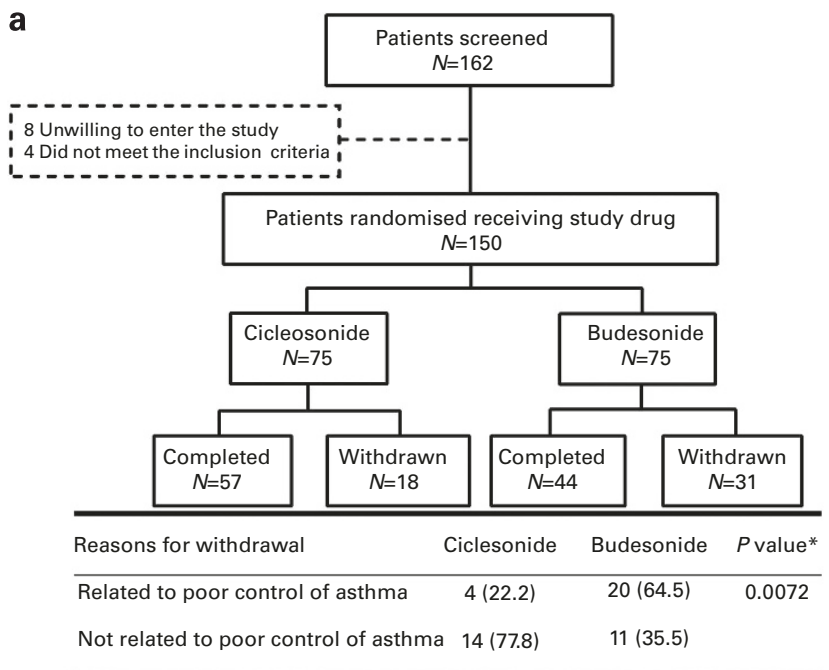

Data express as number (\%). *Fisher's exact test.

b

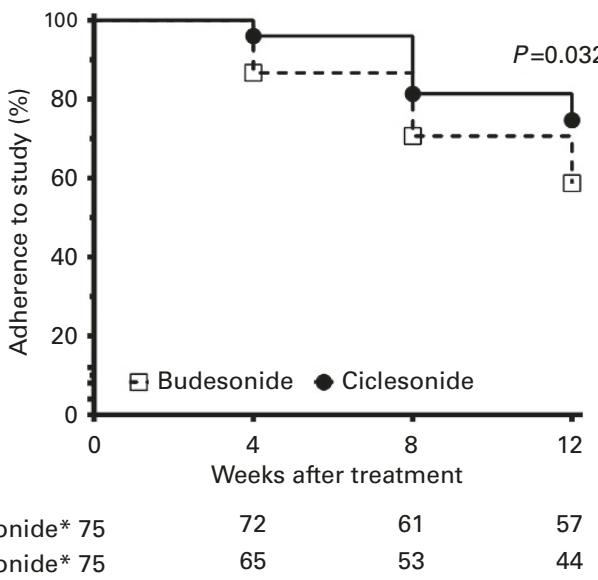

Figure 2. (a) Flowchart of patient disposition. Withdrawal due to poor control of asthma involved $64.5 \%$ of patients in the budesonide group but only $22.2 \%$ of patients in the ciclesonide group. (b) Percentage of patient adherence to the study after 4, 8 and 12 weeks of treatment in the ciclesonide and budesonide groups. The percentage of adherence to the study was significantly decreased in the budesonide group compared with the ciclesonide group until the end of the study. The $P$ value was calculated by means of the log-rank (Mantel-Cox) test. estimating equations (GEE) were applied to analyse the difference between treatment groups at each time point using SPSS v20 software (IBM, Armonk, NY, USA). Patient adherence to study was constructed by the Kaplan-Meier method and the curves were compared using the log rank test. A $P$ value $<0.05$ was considered significant.

\section{RESULTS}

Patient characteristics

A total of 150 patients (48.7\% females) aged $19-75$ years (mean, 53.4 years) were randomised to the $\mathrm{CIC}$ group $(n=75)$ and the BUD group $(n=75)$. Table 1 summarises the baseline characteristics of all patients who were enrolled into the study on Visit 2. There was no significant difference in gender, age, body height, BMI, smoking status, ACT score and lung function between the two patient groups (Table 1). There were no significant changes in lung function test and ACT score between Visit 1 and Visit 2.

\section{Adherence to the study}

Patients in the CIC group had a higher rate of treatment adherence $(57 / 75,76 \%)$ than those in the BUD group (44/75, $59 \%, P=0.03$ ) (Figure $2 \mathrm{~b}$ ). In all nonadherent patients, 20 of 31 $(65 \%)$ in the BUD group and 4 of $18(22 \%)$ in the CIC group withdrew from the study because of poor control of asthma $(P=0.007)$ (Figure 2a). As a whole, $27 \%$ of patients in the BUD group and $5 \%$ in the $\mathrm{CIC}$ group withdrew from the step-down therapy because of poor control of asthma $(P=0.002)$.

\begin{tabular}{|c|c|c|c|}
\hline & $\begin{array}{c}\text { Ciclesonide } \\
(\mathrm{N}=75)\end{array}$ & $\begin{array}{c}\text { Budesonide } \\
\qquad(\mathrm{N}=75)\end{array}$ & $\mathrm{P}$ value \\
\hline Gender, F (\%) & $38(50.7)$ & $35(46.7)$ & 0.624 \\
\hline Age, years & $51.2 \pm 18.3$ & $55.5 \pm 15.4$ & 0.125 \\
\hline Body height, $\mathrm{cm}$ & $160.0 \pm 9.4$ & $161.1 \pm 8.0$ & 0.426 \\
\hline Body weight, kg & $62.8 \pm 9.8$ & $66.0 \pm 13.4$ & 0.092 \\
\hline $\mathrm{BMI}, \mathrm{kg} / \mathrm{m}^{2}$ & $24.5 \pm 3.3$ & $25.4 \pm 3.3$ & 0.195 \\
\hline Smoking status & & & 1.000 \\
\hline Nonsmoker, $n$ (\%) & $66(88.0)$ & $65(86.7)$ & \\
\hline Ex-smokers, $n(\%)^{\mathrm{a}}$ & $9(12.0)$ & $10(813.3)$ & \\
\hline \multicolumn{4}{|l|}{ Pulmonary function } \\
\hline FVC, I & $2.9 \pm 1.1$ & $2.9 \pm 0.9$ & 0.942 \\
\hline FVC, pred. \% & $92.3 \pm 20.1$ & $92.1 \pm 21.5$ & 0.958 \\
\hline $\mathrm{FEV}_{1}$ I & $2.2+0.9$ & $2.1+0.7$ & 0.424 \\
\hline $\mathrm{FEV}_{1}$, pred. $\%$ & $82.6 \pm 19.8$ & $81.6 \pm 19.0$ & 0.744 \\
\hline $\mathrm{FEV}_{1} / \mathrm{FVC}, \%$ & $74.6 \pm 12.1$ & $71.9 \pm 12.0$ & 0.173 \\
\hline MMEF, I/s & $1.9 \pm 1.2$ & $1.7 \pm 0.9$ & 0.075 \\
\hline \multicolumn{4}{|l|}{ Initial diagnosis of asthma } \\
\hline FVC, I & $2.4 \pm 0.8$ & $2.4 \pm 0.7$ & 0.929 \\
\hline FVC, pred. \% & $74.3 \pm 15.4$ & $74.7 \pm 15.6$ & 0.868 \\
\hline $\mathrm{FEV}_{1}, \mathrm{I}$ & $1.6 \pm 0.6$ & $1.6 \pm 0.5$ & 0.776 \\
\hline $\mathrm{FEV}_{1}$, pred. $\%$ & $59.5 \pm 13.0$ & $59.9 \pm 16.8$ & 0.885 \\
\hline Change of $\mathrm{FEV}_{1}, \%^{\mathrm{b}}$ & $22.9 \pm 7.6$ & $22.4 \pm 7.3$ & 0.661 \\
\hline $\mathrm{FEV}_{1} / \mathrm{FVC}, \%$ & $67.6 \pm 11.3$ & $59.9 \pm 16.8$ & 0.399 \\
\hline ACT score & $24.0 \pm 1.0$ & $24.0 \pm 0.9$ & 0.867 \\
\hline \multicolumn{4}{|l|}{ Previous medicine } \\
\hline Seretide, \% & $66(88.0)$ & $62(82.7)$ & 0.356 \\
\hline Symbicort, \% & $9(12.0)$ & $13(17.3)$ & \\
\hline
\end{tabular}

Abbreviations: $\mathrm{ACT}$, asthma control test; $\mathrm{F}$, female; $\mathrm{FEV}_{1}$, forced expiratory volume in $1 \mathrm{~s}$; FVC, forced expiratory capacity; MMEF, maximum midexpiratory flow; pred., predicted value.

${ }^{\text {a S}}$ Smoking history was less than 10 pack-years.

${ }^{\mathrm{b}} \mathrm{FEV}_{1}$ was obtained 15 minutes after inhaled salbutamol $(400 \mu \mathrm{g})$. Data are expressed as mean \pm s.d. or number (\%). 
Pulmonary function tests

Patients in the CIC group maintained a stable FVC throughout the 12-week treatment, whereas that of patients receiving BUD decreased after 4 weeks of treatment (2.8I, 95\% confidence interval $(\mathrm{Cl}), 2.5-3.0 \mathrm{I}, n=65)$ compared with baseline $(2.9 \mathrm{I}, 95 \% \mathrm{Cl}$, 2.7-3.1, $n=75$ ) (Figure 3a). However, there was no significant difference between the two groups throughout the 12 weeks of treatment. The $\mathrm{FEV}_{1}$ in the $\mathrm{CIC}$ group remained stable throughout the treatment period (Figure 3b). The $\mathrm{FEV}_{1}$ (before bronchodilators) of the $\mathrm{ClC}$ group $(2.2 \mathrm{l}, 95 \% \mathrm{Cl}, 2.0-2.4 \mathrm{IL}, n=72)$ was significantly higher than that of the BUD group $(1.9 \mathrm{l}, 95 \% \mathrm{Cl}$, 1.7-2.1 I, $n=65, P=0.02$, Figure $3 \mathrm{~b})$ at 4 weeks and at the end of 12 weeks $(2.0 \mathrm{I}, 95 \% \mathrm{Cl}, 1.8-2.3 \mathrm{I}, n=44, P=0.03$ ) of step-down therapy (Figure $3 \mathrm{~b}$ ). Figure 3 shows only changes in $\mathrm{FEV}_{1}$ and FVC of patients who were adherent to either group and does not include data of patients who withdrew from the study. In the BUD group, patients who withdrew at 8 weeks after treatment (Visit 4) because of poor control of asthma had significantly lower FEV $(1.5 \mathrm{I}, 95 \% \mathrm{Cl}, 1.1-1.8, n=9)$ compared with patients adherent to the step-down therapy or who withdrew for reasons not related to poor control of asthma $(2.0 \mathrm{l}, 95 \% \mathrm{Cl}, 1.8-2.1, n=66, P=0.04)$.
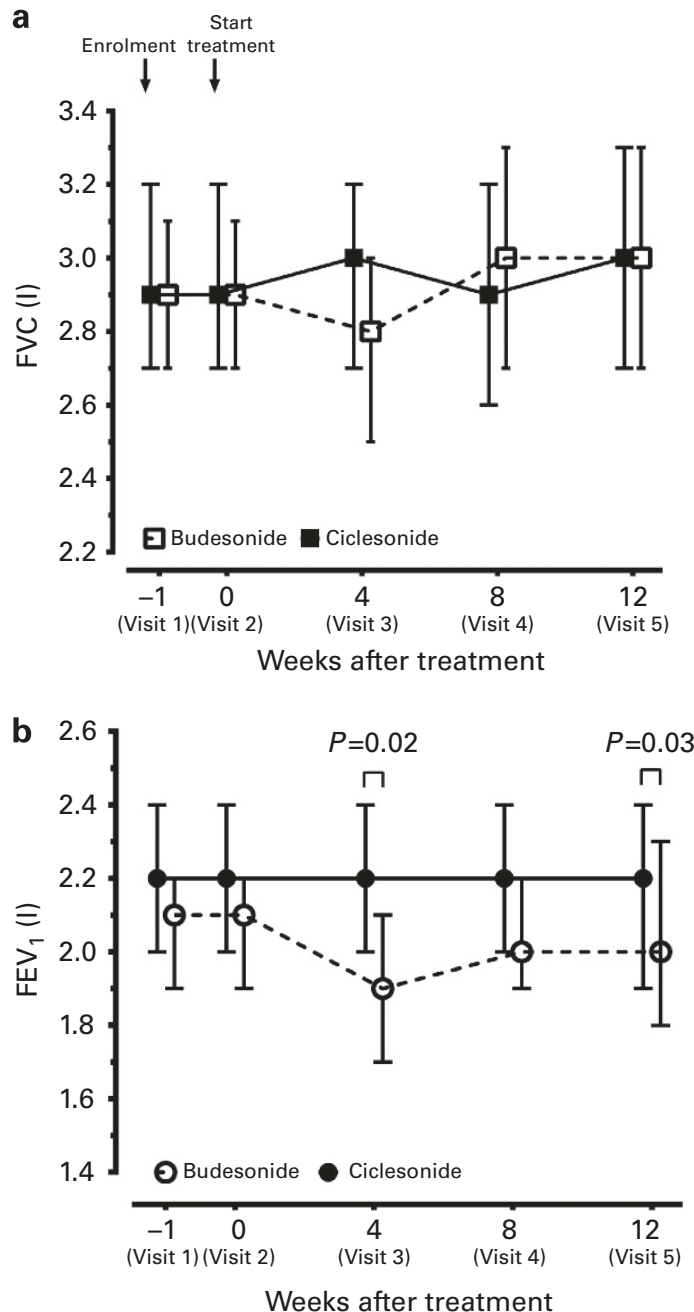

Figure 3. Mean $( \pm 95 \%$ confidence interval, $\mathrm{Cl})$ change from baseline in (a) FVC and (b) FEV 1 after 4 weeks, 8 weeks and 12 weeks of treatment in the budesonide (BUD) and ciclesonide (CIC) groups. The $P$ values were calculated by generalised estimating equations (GEE).
In the CIC group, patients maintained MMEF, a measurement of the small airway function, during the step-down therapy. The MMEF in the CIC group was higher than that of the BUD group $(P=0.02)$, especially after 4 and 8 weeks $(\mathrm{ClC}, 2.0 \mathrm{l} / \mathrm{s}, 95 \% \mathrm{Cl}$, $2.3-1.6 \mathrm{l} / \mathrm{s}, n=61$ vs. BUD, $1.4 \mathrm{l} / \mathrm{s}, 95 \% \mathrm{Cl}, 1.6-1.2 \mathrm{l} / \mathrm{s}, n=53$, $P=0.04)$ (Figure 4).

\section{ACT score}

Figure 5 shows the difference in ACT scores among asthma patients in the CIC and BUD groups. The ACT scores were not significantly different between the two groups at baseline, but improved in the $\mathrm{CIC}$ group after 4 and 8 weeks of treatment compared with baseline ( $P=0.02$ and 0.04 , respectively).

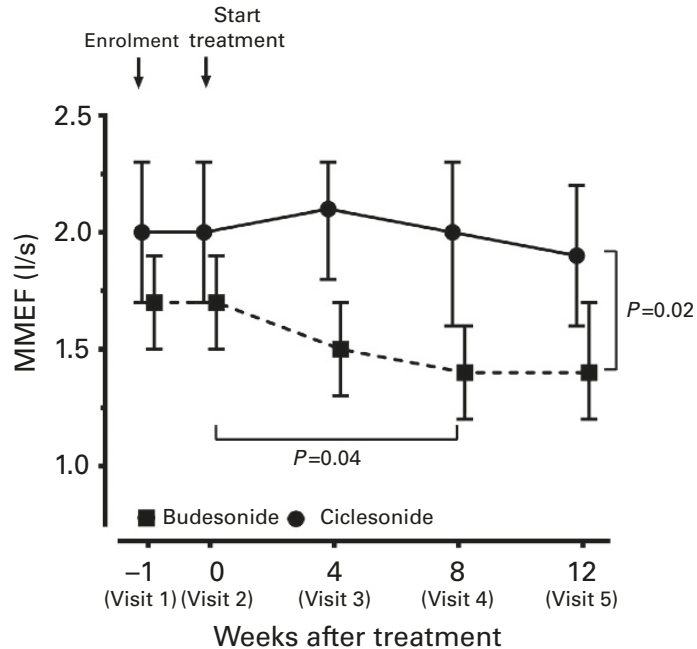

Figure 4. Mean $( \pm 95 \% \mathrm{Cl})$ change from baseline in maximal midexpiratory flow (MMEF) after 4 weeks, 8 weeks and 12 weeks of treatment in the ciclesonide (CIC) and budesonide (BUD) groups. Generalised estimating equations (GEE) were used for comparison between two groups. The $P$ values are indicated.

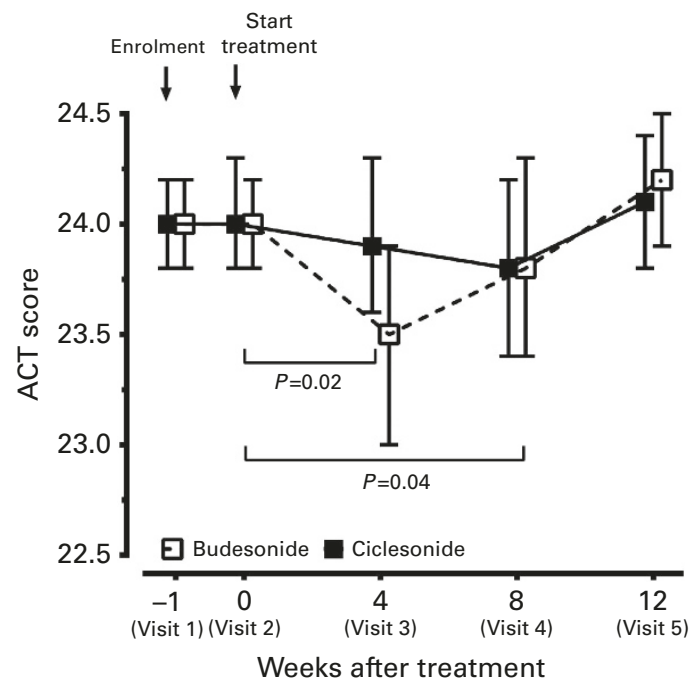

Figure 5. Asthma control test (ACT) scores after 4, 8 and 12 weeks of treatment compared with baseline. Data were expressed as mean $\pm 95 \% \mathrm{Cl}$. The $P$ values were calculated by generalised estimating equations (GEE). 
Table 2. Summary of the patients' and physicians' assessment of treatment

\begin{tabular}{lccc}
\hline & $\begin{array}{c}\text { Ciclesonide } \\
(\mathrm{N}=63)\end{array}$ & $\begin{array}{c}\text { Budesonide } \\
(\mathrm{N}=61)\end{array}$ & $\mathrm{P}$ value \\
& $12(20.8)$ & $3(4.9)$ & 0.02 \\
\hline Summary of the patients' & assessment of treatment & \\
Very satisfied (\%) & $32(50.0)$ & $26(42.6)$ & \\
Satisfied (\%) & $15(29.2)$ & $20(32.8)$ & \\
Neutral (\%) & $4(6.3)$ & $10(16.4)$ & \\
Dissatisfied (\%) & $0(0.0)$ & $2(3.3)$ & \\
Very dissatisfied (\%) & & & \\
& & & \\
Summary of the physicians' & assessment of treatment & \\
Very satisfied (\%) & $12(19.4)$ & $2(3.3)$ & 0.002 \\
Satisfied (\%) & $33(52.4)$ & $29(47.5)$ & \\
Neutral (\%) & $15(23.8)$ & $28(29.5)$ & \\
Dissatisfied (\%) & $3(4.8)$ & $11(18.0)$ & \\
Very dissatisfied (\%) & $0(0.0)$ & $1(1.6)$ & \\
\hline Data are expressed as number (\%). & \\
a'Chi-square test. & & \\
\hline
\end{tabular}

Patients' satisfaction rating and physicians' assessment

At the end of treatment, 63 patients treated with $\mathrm{CIC}$ and 61 patients treated with BUD were asked to rate their overall satisfaction (very satisfied, satisfied, neutral, dissatisfied, very dissatisfied) with the trial medication in managing asthma. More patients in the $\mathrm{CIC}$ group (70\%) were at least satisfied with their treatment, compared with $47.5 \%$ of patients in the BUD group $(P=0.02)$. There was also a statistically significant difference in the physicians' assessment rating in favour of $\mathrm{CIC}$ treatment $(P=0.002)$ (Table 2).

\section{DISCUSSION}

Main findings

This study demonstrated that asthmatic patients treated with $\mathrm{CIC}$ for step-down therapy fared better than those treated with BUD. After switching to $\mathrm{CIC}$, patients maintained more stable lung function values such as $\mathrm{FEV}_{1}$ and MMEF. Patients treated with BUD, despite a higher equivalent dose of corticosteroids, suffered from more frequent asthma symptoms, resulting in increased withdrawal rates. Patients in the CIC group showed higher adherence, a better patient satisfaction rate and more favourable physician assessment in terms of asthma control when compared with patients in the BUD group. To date, this is the first study that compares a step-down therapy strategy between mono-ICSs from a combination therapy with ICSs and LABAs in patients with wellcontrolled mild to moderate asthma. Discontinuing LABA therapy in asthmatic patients under a combination of ICSs and LABAs is the main cause contributing to increased asthma-associated impairment, ${ }^{18}$ but in the studies reviewed fluticasone and BUD were the maintenance ICSs used. Our study indicates that this loss of asthma control during LABA step-off is less likely if the maintenance ICS is CIC.

Interpretation of findings in relation to previously published work Asthma may be regarded as a disease with three interrelated components: airway inflammation, smooth muscle dysfunction, and airway remodelling. The first two can be effectively treated with corticosteroids and LABAs, respectively. ${ }^{23,24}$ Despite the lack of an effective treatment for airway remodelling, it is believed that better outcomes can be achieved by appropriate management of asthma. Studies have shown that complementary actions exist between corticosteroids and LABAs, including the differential inhibition of the inflammatory cascade and mutual activation of their respective receptors. ${ }^{25,26}$ There is compelling evidence showing that, despite the availability of asthma treatment guidelines ${ }^{27}$ and effective treatments, asthma still remains undertreated. ${ }^{28}$ There is evidence supporting the view that starting with a moderate dose of ICS and then reducing the dose once asthma control has been achieved is as effective as starting with a very high dose. ${ }^{29}$ However, there is much less evidence to consider when making recommendations about the best approach to take when stepping down treatment. The GINA guideline ${ }^{27}$ states that step-down treatment should occur only 'by agreement between patient and health-care professional, with full discussion of potential consequences including reappearance of symptoms and increased risk of exacerbations.' This is because once the ICS dose is reduced there may be a slow deterioration in asthma control. ${ }^{30}$ Considering the side/detrimental effects of the oral or inhalation route of corticosteroids, $\mathrm{CIC}$, a prodrug whose active metabolite shows very pronounced plasma protein binding, ${ }^{9}$ low free plasma concentrations and, consequently, low cortisol suppression, ${ }^{31}$ may be an optimal choice for patients for asthma control during step-down therapy. Our results have shown that patients taking $\mathrm{ClC}$ had better asthma control over those taking BUD, indicating that $\mathrm{CIC}$ may be a good option during stepdown therapy.

Small airways play an important role in inflammation and obstruction in asthma, which contributes to the severity of airway hyperresponsiveness as well as asthma control. ${ }^{31}$ The advantage of small-particle ICSs is that they are able to reach the small airways and target the site of inflammation, consequently resulting in improvement of mid-expiratory flow rates, ${ }^{32}$ decreased alveolar exhaled nitric oxide levels, ${ }^{7}$ decreased markers of inflammation in exhaled breath condensate ${ }^{16}$ and increased efficacy. ${ }^{33}$ However, it has been demonstrated that ICSs with chlorofluorocarbon (CFC) formulation, like CFC-BUD, have larger particles and are predominantly deposited in the central airways and not in the lung periphery. ${ }^{13,34}$ Our study demonstrated that the MMEF, a parameter in the detection of obstructive small airway obstruction, ${ }^{35,36}$ had a gradually significant decrease from the start of treatment up to 8 weeks of the study period in the BUD group, when patients with asthma received step-down therapy with BUD from ICS and LABA (Figure 4). The present study has shown the beneficial effects of $\mathrm{CIC}$, the small-particle ICS, on small airway involvement in asthma, even without the protection of a LABA bronchodilator. In our study, CIC provides effective or equivalent asthma control at much lower doses $(320 \mu \mathrm{g}$ daily) compared with CFC-propelled BUD $(800 \mu \mathrm{g}$ daily) in mild to moderate asthma patients after step-down therapy.

Previous studies reported that subjects with asthma who smoke have an attenuated response to ICSs, ${ }^{37,38}$ including less increase of morning PEF and FEV 1 and increased airway hyperreactivity. The potential mechanisms by which habitual cigarette smoking may induce insensitivity to corticosteroids include enhanced neutrophil-mediated inflammation in smokers. ${ }^{39}$ Thus, lung deposition of ICS among smokers and nonsmokers may underlie our findings on the differential effects of CIC/BUD on MMEF. However, current smokers have been excluded in this study.

In the BUD group (Figure 3), the value of $\mathrm{FEV}_{1}$ started to reduce at 4 weeks of treatment throughout the study. However, the extent of $\mathrm{FEV}_{1}$ decline did not reach statistical significance compared with the baseline. Data of patients who withdrew from the study because of poor asthma control with significantly lower values of $\mathrm{FEV}_{1}$ were not included in the analysis. The data of FEV shown in Figure 3 represent the change in $\mathrm{FEV}_{1}$ of patients who were adherent to step-down therapy or who withdrew for reasons not related to poor asthma control after 4 weeks of treatment. Although more than half of the patients (58.7\%) were still adherent to BUD therapy during the step-down from LABA, CIC treatment was apparently better than BUD treatment in terms of 
adherence rate (76\%) and $\mathrm{FEV}_{1}$ and $\mathrm{MMEF}$ improvement, despite the equivalent corticosteroid dose of BUD being twice that of $\mathrm{CIC}$.

More than $70 \%$ of patients in the CIC group were satisfied with their treatment, whereas only $6.3 \%$ of patients reported being dissatisfied. In comparison, only $47.5 \%$ of patients in the BUD group were satisfied with their treatment and $19.7 \%$ were dissatisfied. During the study period, $27 \%$ (20 of 75 ) of patients in the BUD group but only $5 \%$ (5 of 75 ) of patients in the $\mathrm{CIC}$ group dropped out because of asthmatic symptoms. The physicians' assessment showed the same trend, with better satisfaction $(71.8 \%)$ rates seen in the CIC group over the BUD group (50.8\%). These findings support the notion that the use of $\mathrm{CIC}$ is safe and tolerable in the treatment of asthma.

\section{Strengths and limitations of this study}

The limitation of this study was its small study population as well as the limited treatment period. As such, this study is unable to demonstrate the long-term efficacy along with safety issues in these groups of asthma patients. Asthma comprises a heterogeneous group of diseases. The baseline data for this study did not include airway hyperresponsiveness or the extent of airway inflammation, which may have an impact on the success rate of step-down therapy. Nevertheless, the results here reveal that stepdown therapy with small-particle ICS and the once-daily administration improves adherence rate as well as asthma control, compared with conventional ICS.

Implications for future research, policy and practice

In future, a prospective and crossover study on a larger number of patients is needed to elucidate whether the different effectiveness of CIC compared with BUD in step-down therapy from ICS and LABA combination is attributable to treatment compliance (once daily versus twice daily) or drug efficacy (small particle versus larger particle). More detailed stratification of patients in terms of asthma severity, airway reversibility, airway hyperresponsiveness and extent of airway inflammation (such as exhaled NO) may be beneficial in predicting or improving success in step-down therapy with ICS. However, step-down therapy may be started with ICS only once asthma control has been achieved by ICS and LABA combination therapy. Then, CIC may be an optimal option.

\section{Conclusions}

$\mathrm{CIC}$ as a step-down therapy from ICS and LABA combination for asthma control is safe, effective and tolerable, with good compliance and a high level of patient satisfaction.

\section{ACKNOWLEDGEMENTS}

The authors gratefully acknowledge financial support from a Chang Gung Memorial Hospital Research Project Grant and from Holling Bio-Pharma Corp.

\section{CONTRIBUTIONS}

K-CC, Y-LC, J-YH, M-SL, C-HL contributed to data collection, interpretation and analysis. P-CC performed part of the design work, and drafting of the article C-LC contributed to the acquisition of data and statistical analysis. C-HW and $\mathrm{H}$-PK took the substantial responsibility of the main concept and design of this work and contributed to the analysis and interpretation of data and final approval of the version to be published. C-HW was the principal investigator who initiated and supervised the study. K-CC, J-YH, M-SL and C-HL were the co-investigators of this project. $\mathrm{C}-\mathrm{HW}$ is the guarantor.

\section{COMPETING INTERESTS}

The authors declare no conflict of interest.

\section{FUNDING}

This study was supported by Chang Gung Memorial Hospital Research Project Grant, XMRPG380441-2. The funding is sponsored by Holling Bio-Pharma Corp., a Taiwan local agency of ciclesonide, and went through the Chang Gung Memorial Hospital.

\section{REFERENCES}

1 Jeffery PK, Wardlaw AJ, Nelson FC, Collins JV, Kay AB. Bronchial biopsies in asthma. An ultrastructural, quantitative study and correlation with hyperreactivity. Am Rev Respir Dis 1989; 140: 1745-1753.

2 Laitinen LA, Laitinen A, Haahtela T. Airway mucosal inflammation even in patients with newly diagnosed asthma. Am Rev Respir Dis 1993; 147: 697-704.

3 Vignola AM, Chanez P, Bonsignore G, Godard P, Bousquet J. Structural consequences of airway inflammation in asthma. J Allergy Clin Immunol 2000; 105: S514-S517.

4 Ulrik CS. Outcome of asthma: longitudinal changes in lung function. Eur Respir J 1999; 13: 904-918.

5 Postma DS, Sevette C, Martinat Y, Schlösser N, Aumann J, Kafé H. Treatment of asthma by the inhaled corticosteroid ciclesonide given either in the morning or evening. Eur Respir J 2001; 17: 1083-1088.

6 Deeks ED, Perry CM. Ciclesonide: a review of its use in the management of asthma. Drugs 2008; 68: 1741-1770.

7 Cohen J, Douma WR, ten Hacken NH, Vonk JM, Oudkerk M, Postma DS. Ciclesonide improves measures of small airway involvement in asthma. Eur Respir J 2008; 31: 1213-1220.

8 Korenblat PE. Ciclesonide and the treatment of asthma. Expert Opin Pharmacother 2010; 11: 463-479.

9 Derendorf H, Nave R, Drollmann A, Cerasoli F, Wurst W. Relevance of pharmacokinetics and pharmacodynamics of inhaled corticosteroids to asthma. Eur Respir J 2006; 28: 1042-1050.

10 Derendorf $\mathrm{H}$. Pharmacokinetic and pharmacodynamic properties of inhaled ciclesonide. J Clin Pharmacol 2007; 47: 782-789.

11 Nave R, Bethke TD, van Marle SP, Zech K. Pharmacokinetics of [14C]ciclesonide after oral and intravenous administration to healthy subjects. Clin Pharmacokinet 2004; 43: 479-486.

12 Rohatagi S, Arya V, Zech K, Nave R, Hochhaus G, Jensen BK et al. Population pharmacokinetics and pharmacodynamics of ciclesonide. J Clin Pharmacol 2003; 43: $365-378$.

13 Gentile DA, Skoner DP. New asthma drugs: small molecule inhaled corticosteroids Curr Opin Pharmacol 2010; 10: 260-265.

14 Newman S, Salmon A, Nave R, Drollmann A. High lung deposition of 99mTclabeled ciclesonide administered via HFA-MDI to patients with asthma. Respir Med 2006; 100: 375-384.

15 Leach C, Colice GL, Luskin A. Particle size of inhaled corticosteroids: does it matter? J Allergy Clin Immunol 2009; 124: S88-S93.

16 Robroeks CM, van de Kant KD, van Vliet D, Kester AD, Hendriks HJ, Damoiseaux JG et al. Comparison of the anti-inflammatory effects of extra-fine hydrofluoroalkanebeclomethasone vs fluticasone dry powder inhaler on exhaled inflammatory markers in childhood asthma. Ann Allergy Asthma Immunol 2008; 100: 601-607.

17 National Asthma Education and Prevention Program. Expert Panel Report 3 (EPR-3): Guidelines for the diagnosis and management of asthma-summary 2007 J Allergy Clin Immunol 2007; 120(Suppl): S94-S138.

18 Brozek JL, Kraft M, Krishnan JA, Cloutier MM, Lazarus SC, Li JT et al. Long-acting $\beta 2$-agonist step-off in patients with controlled asthma. Arch Intern Med 2012; 172 1365-1375.

19 Chowdhury BA, Dal Pan G. The FDA and safe use of long-acting $\beta$-agonists in the treatment of asthma. N Engl J Med 2010; 362: 1169-1171.

20 American Thoracic Society. Standards for the diagnosis and care of patients with chronic obstructive pulmonary disease (COPD) and asthma (official statement adopted by the ATS Board of Directors, November 1986). Am Rev Respir Dis 1987; 136: 225-244.

21 Schatz M, Sorkness CA, Li JT, Marcus P, Murray JJ, Nathan RA et al. Asthma control test: reliability, validity, and responsiveness in patients not previously followed by asthma specialists. J Allergy Clin Immunol 2006; 117: 549-556.

22 Nathan RA, Sorkness CA, Kosinski M, Schatz M, Li JT, Marcus P et al. Development of the asthma control test: a survey for assessing asthma control. J Allergy Clin Immunol 2004; 113: 59-65.

23 Koopmans JG, Lutter R, Jansen HM, van der Zee JS. Adding salmeterol to an inhaled corticosteroid: long term effects on bronchial inflammation in asthma. Thorax 2006; 61: 306-312.

24 Wallin A, Sue-Chu M, Bjermer L, Ward J, Sandström T, Lindberg A et al. Effect of inhaled fluticasone with and without salmeterol on airway inflammation in asthma. J Allergy Clin Immunol 2003; 112: 72-78. 
25 Usmani OS, Ito K, Maneechotesuwan K, Ito M, Johnson M, Barnes PJ et al. Glucocorticoid receptor nuclear translocation in airway cells after inhaled combination therapy. Am J Respir Crit Care Med 2005; 172: 704-712.

26 Black JL, Oliver BG, Roth M. Molecular mechanisms of combination therapy with inhaled corticosteroids and long-acting beta-agonists. Chest 2009; 136: 1095-1100.

27 Bateman ED, Hurd SS, Barnes PJ, Bousquet J, Drazen JM, FitzGerald M et al. Global strategy for asthma management and prevention: GINA executive summary. Eur Respir J 2008; 31: 143-178.

28 Rabe KF, Adachi M, Lai CK, Soriano JB, Vermeire PA, Weiss KB et al. Worldwide severity and control of asthma in children and adults: the global asthma insights and reality surveys. J Allergy Clin Immunol 2004; 114: 40-47.

29 Reddel HK, Jenkins CR, Marks GB, Ware SI, Xuan W, Salome CM et al. Optimal asthma control, starting with high doses of inhaled budesonide. Eur Respir J 2000; 16: 226-235.

30 Juniper EF, Kline PA, Vanzieleghem MA, Hargreave FE. Reduction of budesonide after a year of increased use: a randomized controlled trial to evaluate whether improvements in airway responsiveness and clinical asthma are maintained. J Allergy Clin Immunol 1991; 87: 483-489.

31 Szefler S, Rohatagi S, Williams J, Lloyd M, Kundu S, Banerji D. Ciclesonide, a novel inhaled steroid, does not affect hypothalamic-pituitary-adrenal axis function in patients with moderate-to-severe persistent asthma. Chest 2005; 128 1104-1114.

32 Bergeron C, Hauber HP, Gotfried M, Newman K, Dhanda R, Servi RJ et al. Evidence of remodeling in peripheral airways of patients with mild to moderate asthma: effect of hydrofluoroalkane-flunisolide. J Allergy Clin Immunol 2005; 116: 983-989.

33 Juniper EF, Price DB, Stampone PA, Creemers JP, Mol SJ, Fireman P. Clinically important improvements in asthma-specific quality of life, but no difference in conventional clinical indexes in patients changed from conventional beclomethasone dipropionate to approximately half the dose of extrafine beclomethasone dipropionate. Chest 2002; 121: 1824-1832.

34 Hamid Q. Pathogenesis of small airways in asthma. Respiration 2012; 84: 4-11.

35 Simon MR, Chinchilli VM, Phillips BR, Sorkness CA, Lemanske RF Jr, Szefler SJ et al. Forced expiratory flow between $25 \%$ and $75 \%$ of vital capacity and FEV1/forced vital capacity ratio in relation to clinical and physiological parameters in asthmatic children with normal FEV1 values. J Allergy Clin Immunol 2010; 126: 527-534.

36 Ciprandi G, Cirillo I. Forced expiratory flow between $25 \%$ and $75 \%$ of vital capacity may be a marker of bronchial impairment in allergic rhinitis. J Allergy Clin Immunol 2011; 127: 549.

37 Chalmers GW, Macleod KJ, Little SA, Thomson L, McSharry CP, Thomson NC. Influence of cigarette smoking on inhaled corticosteroid treatment in mild asthma. Thorax 2002; 57: 226-230.

38 Tomlinson JEM, McMahon AD, Chaudhuri R, Thompsom JM, Wood SF, Thomson NC. Efficacy of low and high dose inhaled corticosteroid in smokers versus nonsmokers with mild asthma. Thorax 2005; 60: 282-287.

39 Chalmers GW, MacLeod KJ, Thomson L, Little SA, McSharry C, Thomson NC. Smoking and airway inflammation in patients with mild asthma. Chest 2001; 120: 1917-1922.

(c) (2) This work is licensed under a Creative Commons AttributionNonCommercial-ShareAlike 4.0 Unported License. The images or other third party material in this article are included in the article's Creative Commons license, unless indicated otherwise in the credit line; if the material is not included under the Creative Commons license, users will need to obtain permission from the license holder to reproduce the material. To view a copy of this license, visit http:// creativecommons.org/licenses/by-nc-sa/4.0/ 